\title{
Evaluation of Forecasted Southeast Pacific Stratocumulus in the NCAR, GFDL, and ECMWF Models
}

\author{
Cécile Hannay, David L. Williamson, James J. Hack, Jeffrey T. Kiehl, \\ AND JERRY G. OLSON \\ National Center for Atmospheric Research,* Boulder, Colorado \\ STEPHEN A. KLEIN \\ Lawrence Livermore National Laboratory, Livermore, California \\ CHRISTOPHER S. BRETHERTON \\ Department of Atmospheric Sciences, University of Washington, Seattle, Washington \\ MARTIN KÖHLER \\ European Centre for Medium-Range Weather Forecasts, Reading, United Kingdom
}

(Manuscript received 14 February 2008, in final form 10 November 2008)

\begin{abstract}
Forecasts of southeast Pacific stratocumulus at $20^{\circ} \mathrm{S}$ and $85^{\circ} \mathrm{W}$ during the East Pacific Investigation of Climate (EPIC) cruise of October 2001 are examined with the ECMWF model, the Atmospheric Model (AM) from GFDL, the Community Atmosphere Model (CAM) from NCAR, and the CAM with a revised atmospheric boundary layer formulation from the University of Washington (CAM-UW). The forecasts are initialized from ECMWF analyses and each model is run for 3-5 days to determine the differences with the EPIC field observations.

Observations during the EPIC cruise show a well-mixed boundary layer under a sharp inversion. The inversion height and the cloud layer have a strong and regular diurnal cycle. A key problem common to the models is that the planetary boundary layer (PBL) depth is too shallow when compared to EPIC observations. However, it is suggested that improved PBL depths are achieved with more physically realistic PBL schemes: at one end, CAM uses a dry and surface-driven PBL scheme and produces a very shallow PBL, while the ECWMF model uses an eddy-diffusivity/mass-flux approach and produces a deeper and bettermixed PBL. All the models produce a strong diurnal cycle in the liquid water path (LWP), but there are large differences in the amplitude and phase when compared to the EPIC observations. This, in turn, affects the radiative fluxes at the surface and the surface energy budget. This is particularly relevant for coupled simulations as this can lead to a large SST bias.
\end{abstract}

\section{Introduction}

Stratocumulus clouds strongly influence the global climate because of their radiative effects. These clouds

* The National Center for Atmospheric Research is sponsored by the National Science Foundation.

Corresponding author address: Cécile Hannay, National Center for Atmospheric Research, 1850 Table Mesa Drive, Boulder, CO 80305.

E-mail: hannay@ucar.edu form over oceans with cold sea surface temperature (SST). They form at the top of the planetary boundary layer (PBL) and are capped by a sharp inversion of temperature and moisture (e.g., Klein and Hartmann 1993). Because of their high reflectivity, stratocumulus clouds strongly decrease the solar radiation that reaches the surface, and, because of their large optical thickness, they emit like a blackbody in the infrared. The net radiative effect is a strong cooling of the surface and the PBL relative to clear-sky regions. These radiative properties make stratocumulus a crucial factor in the surface and top-of-atmosphere energy balance such that 
their realistic representation is essential for climate modeling.

Stratocumulus exhibit a diurnal cycle in the cloud amount and liquid water path (LWP) with an early morning maximum and an early afternoon minimum in both quantities (Wood et al. 2002). At night, the strong longwave cooling near the top of the cloud creates turbulence. This produces a well-mixed PBL, which transports moisture from the surface into the PBL and maintains the cloud. During daytime, in-cloud absorption of solar radiation largely compensates the longwave cooling. As a result, the turbulence decreases after sunrise leading to a decoupling between the cloud and the surface accompanied by a thinning of the cloud layer. The diurnal variations of LWP have a considerable effect upon the earth's radiation budget (e.g., Bergman and Salby 1997), and it is therefore important that general circulation models (GCMs) simulate accurately the diurnal cycle of these clouds. In the southeast Pacific, the diurnal cycle of stratocumulus is very pronounced and stronger than in other stratocumulus regions (Rozendaal et al. 1995; Zuidema and Hartmann 1995; Wood et al. 2002). Other mechanisms may amplify the stratocumulus diurnal cycle in the southeast Pacific. In particular, Garreaud and Muñoz (2004) show that the diurnal cycle in subsidence plays an important role in this region and increases the amplitude of the diurnal cycle of the stratocumulus amount with respect to the cycle forced by radiation alone.

Despite advances in observing and understanding the stratocumulus regimes (e.g., Stevens et al. 2003; Bretherton et al. 2004), the stratocumulus are among the worstsimulated tropical clouds in GCMs (Bony and Dufresne 2005). Cloud amounts are usually underestimated, even when the SSTs are observationally prescribed. Moreover, serious model biases exist in the representation of vertical structure. Several studies assessing stratocumulus in climate and weather forecast models show that the PBL is typically too shallow and the LWP too low compared with observations. Duynkerke and Teixeira (2001) show that the 15-yr European Centre for Medium-Range Weather Forecasts (ECMWF) ReAnalysis (ERA-15; Gibson et al. 1997) strongly underestimates the stratocumulus cloud cover and LWP. They speculate that it is the result of the failure of the model to mix the moisture sufficiently deep enough into the cloud layer, possibly partly because of the poor model vertical resolution. However, Stevens et al. (2007) show that the liquid water path and the PBL depth are also underestimated in ERA-40 (Uppala et al. 2005), despite an enhanced vertical resolution compared to the ERA-15, suggesting that the overly shallow PBL may not simply be a vertical resolution issue. They argue that the inability of the ERA-40 to produce a sufficiently deep PBL comes from its K-profile scheme that does not recognize moist processes, and therefore improvement may be expected by better accounting for moist thermodynamics and representing the entrainment rates. In a study of the southeast Pacific stratocumulus deck, Bretherton et al. (2004) show that the PBL depth and cloud LWP are underestimated in both world-class leading GCMs and operational analyses. Siebesma et al. (2004) have found a similar result in the northeast Pacific and they conclude that the underprediction of clouds is likely due to too intense drizzle and/or too much entrainment. Since the stratocumulus regions have a significant cooling effect on the underlying ocean, an underestimation of the cloud amount causes an overestimation of the net surface heat flux into the ocean. This may contribute to positive SST biases of several degrees in coupled models (Mechoso et al. 1995; Ma et al. 1996; Duynkerke and Teixeira 2001; Kiehl and Gent 2004; Wittenberg et al. 2006; Teixeira et al. 2008). Subsequent coupled feedbacks can then exacerbate the coastal warm SST bias and further reduce the cloudiness, wind speed, evaporation, and upwelling near the model coasts. This is a particular concern for ENSO predictions since such errors can strongly affect the circulation.

A series of large-eddy simulations (LES) and singlecolumn model (SCM) intercomparison studies of stratocumulus and cumulus cloud-top boundary layers based on well-observed test cases has explored some of the reasons behind the low values of LWP. The first intercomparison from the Global Energy and Water Cycle Experiment (GEWEX) Cloud System Study (GCSS) Boundary Layer Cloud Working Group of LES and SCM simulations of nocturnal nonprecipitating stratocumulus (Bechtold et al. 1996; Moeng et al. 1996) shows that in most LES and SCM models the LWP decreases to unrealistically small values after as little as one hour of simulation, suggesting excessive entrainment of dry air. More recently, LES and SCM simulations of the Second Dynamics and Chemistry of the Marine Stratocumulus field study (DYCOMS II) research flight RF01 (Stevens et al. 2003) show that, despite an improvement of entrainment rates, the LWP still differs by an order of magnitude between models (Stevens et al. 2005; Zhu et al. 2005). Duynkerke et al. (2004) have found a similar result in the European Project on Cloud Systems (EUROCS) intercomparison of stratocumulus off the coast of California. Meanwhile, the importance of drizzle in stratocumulus has became more apparent, and an SCM intercomparison of drizzling stratocumulus from the DYCOMS II research flight 02 (vanZanten and 
Stevens 2005) shows that drizzle substantially decreases the LWP for many models (Wyant et al. 2007).

Despite the undeniable value of SCM studies, they are not always able to assess the performance of a physical parameterization within a GCM because there are situations where the systematic errors of the GCM and the SCM differ because of differences in the feedbacks between the dynamics and the physics (Petch et al. 2007). Understanding the causes of the stratocumulus bias in climate simulations is difficult because of the complexity and nonlinear interactions of the processes maintaining the cloud. In situ observations, which are only available for limited periods of time, are difficult to compare with model climatological statistics for the purpose of evaluating parameterization performance. Applying GCMs in short-term forecasts can be extremely valuable because it minimizes the interaction of large nonlinear systematic model errors that grow over time and because forecasts can be evaluated over limited observation periods. The forecast approach is described in Phillips et al. (2004), and it has been successfully used in several studies (Williamson et al. 2005; Boyle et al. 2005; Klein et al. 2006; Williamson and Olson 2007; Boyle et al. 2008). The principle of the method is that if the model is initialized realistically, the systematic errors in short forecasts are predominantly due to parameterization errors. This is because the large-scale circulation is strongly controlled by the initial conditions and stays close to the observed state in these short-range runs. Therefore, it is possible to gain insight into the parameterization deficiencies and to diagnose the processes behind the model climate drift.

Here, we investigate how three climate models and one forecast model and its analysis system represent a region of persistent stratocumulus in global forecasts examined at a column in the southeast Pacific $\left(20^{\circ} \mathrm{S}\right.$, $85^{\circ} \mathrm{W}$ ). This column is well suited for such a study because of the availability of accurate analyses to initialize the forecasts and of observational datasets to evaluate them. The 2001 East Pacific Investigation of Climate (EPIC) cruise provides a 6-day comprehensive observational dataset at this location including surface measurements and remote sensing data (Bretherton et al. 2004). This cruise was the first that effectively sampled multiple diurnal cycles in a pristine marine stratocumulus environment, and it provides a great opportunity to evaluate model forecasts of stratocumulus.

The paper is organized as follows. In section 2 we describe the models, the observational datasets and the forecast experiment settings. In section 3 we consider the forecast results paying special attention to the diurnal cycle. Finally we summarize our conclusions in section 4

\section{Data and model descriptions}

\section{a. Models}

The global models used in this study are the ECMWF model cycle 29r1; the Atmospheric Model version 2 (AM), developed at the Geophysical Fluid Dynamics Laboratory (GFDL); the Community Atmosphere Model, version 3.1 (CAM), developed at the National Center for Atmospheric Research (NCAR); and the CAM with the University of Washington $\mathrm{PBL} /$ shallow convection scheme (CAM-UW). The physical parameterizations of the models are summarized in Table 1. In the following paragraphs, we briefly describe the parameterizations relevant for our purpose. More details about the models can be found in Collins et al. (2004) for CAM, in GFDL Global Atmospheric Model Development Team (2004) for AM, in Bretherton and Park (2009) and Park and Bretherton (2009) for CAM-UW, and in Tompkins et al. (2004) and Köhler (2005) for the ECWMF model. Hereafter, we refer to the models CAM, CAM-UW, and AM as "climate GCMs" as opposed to the ECMWF model, which is a "forecast GCM."

The models determine the cloud fraction and the cloud condensate in various ways. The CAM and CAM-UW determine the cloud fraction diagnostically based on relative humidity, vertical motion, static stability, and convective properties philosophically following Slingo (1987). Their microphysics scheme described in Rasch and Kristjansson (1998) is a bulk scheme with prognostic and conserved liquid and ice mass. This scheme is closed with the large-scale condensation assumptions described in Zhang et al. (2003). The AM uses three prognostic tracers: cloud liquid, cloud ice, and cloud fraction. The cloud macrophysics follows Tiedtke (1993) and the microphysics follows Rotstayn et al. (2000). The ECWMF cloud scheme is based on Tiedtke (1993) and the model prognoses the subgrid-scale variability of total water specific humidity from which cloud fraction and cloud condensate are diagnosed (Tompkins 2002). The ECMWF microphysics are described in Tiedtke (1993).

The boundary layer turbulence and convective schemes also differ among models. All the models have PBL parameterizations for the stable PBL that may play a role in stratocumulus simulations. In CAM, the PBL parameterization is a nonlocal diffusivity $\mathrm{K}$-profile scheme in which the PBL depth is computed explicitly and the profile of diffusion coefficients prescribed below that depth (Holtslag and Boville 1993). The scheme neglects the moist thermodynamics (essentially a "dry" scheme) and is forced exclusively from the surface by the surface buoyancy flux and friction velocity. Convection is represented by two schemes. The deep convective scheme (Zhang and McFarlane 1995) is applied first and acts to 


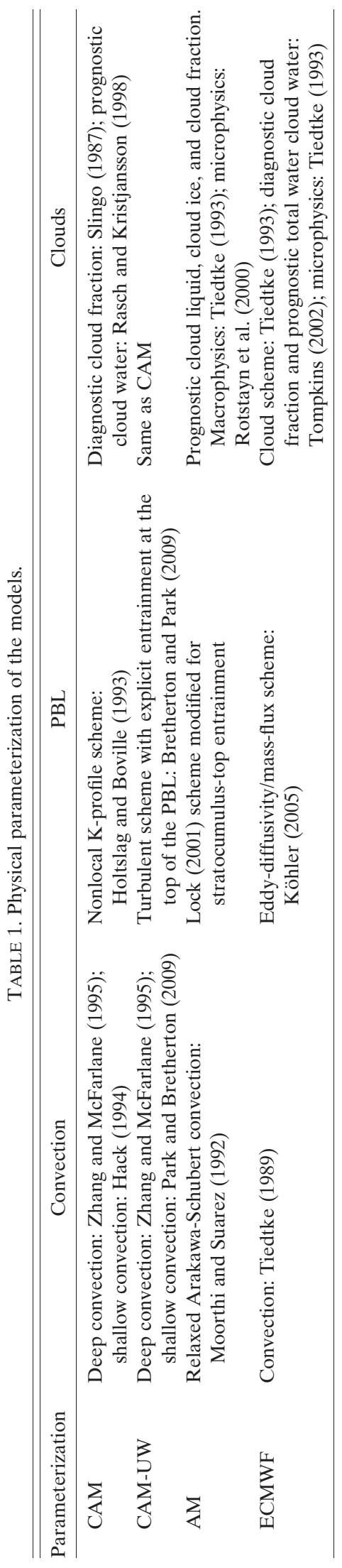

reduce the convective available potential energy (CAPE) in the column over a specified time scale. The remaining local instabilities are removed by a local convective transport scheme (Hack 1994). The Hack scheme mixes triplets of model layers when conditional instability is diagnosed and acts as a moist-adjustment scheme for conditionally unstable layer clouds as well as for cumulus convection. Unlike the CAM, which assumes no direct interaction between turbulence and condensation, the CAM-UW is formulated using moist physics. It determines turbulent diffusivities based on prognostic turbulent kinetic energy (TKE). The turbulent scheme includes explicit entrainment at the top of the PBL (Grenier and Bretherton 2001; Bretherton and Park 2009) and is coupled with a shallow convection scheme that includes the determination of a cloud-base mass flux based on surface TKE and convection inhibition near the cloud base (Park and Bretherton 2009). The AM surface and stratocumulus convective layers are represented by a K-profile scheme with prescribed entrainment rates (Lock et al. 2000) modified for stratocumulus-top entrainment according to Lock (2001) for which the radiatively driven entrainment rate is reduced to a function of the longwave flux divergence across the cloud top and the jump in liquid water virtual potential temperature across the entrainment interface. The ECWMF model uses an eddy-diffusivity/mass-flux approach that combines a K-profile diffusion term with a mass-flux term to describe nonlocal transport (Siebesma and Cuijpers 1995; Siebesma and Teixeira 2000; Soares et al. 2004; Köhler 2005; Angevine 2005; Siebesma et al. 2007). It is formulated in terms of moist variables. The cloud-top entrainment also uses prescribed entrainment rates (Lock et al. 2000). A stratocumulus-topped mixed layer is allowed for a stable lower atmosphere (Klein and Hartmann 1993), otherwise the convection scheme can act. The convection parameterization follows the mass-flux approach described in Tiedtke (1989).

The resolutions of the models are summarized in Table 2. The three climate GCMs (CAM, CAM-UW, and AM) use a horizontal grid interval of about 200$300 \mathrm{~km}$ near the EPIC point while the ECMWF forecast model uses a much finer horizontal resolution $(\sim 40 \mathrm{~km})$. The vertical resolution ranges from 24 vertical levels for AM to 60 levels for the ECWMF model. Table 2 also compares the number of levels in the lowest $1.5 \mathrm{~km}$ above the surface. It shows that the model vertical grids only grossly resolve the PBL, which may contribute to the difficulties models have in reproducing stratocumulus. For instance, CAM at the standard 26-level vertical resolution has only 4 levels in the lowest $1.5 \mathrm{~km}$ of the model. Notice that CAM has 26 vertical levels in the climate runs while the forecast runs were performed 
TABLE 2. Model vertical and horizontal resolutions and number of levels in the lowest $1.5 \mathrm{~km}$ of the troposphere.

\begin{tabular}{|c|c|c|c|c|}
\hline & CAM & CAM-UW & $\mathrm{AM}$ & ECMWF \\
\hline Horizontal resolution & $\mathrm{T} 42\left(\sim 2.8^{\circ} \times 2.8^{\circ}\right)$ & $\mathrm{T} 42\left(\sim 2.8^{\circ} \times 2.8^{\circ}\right)$ & $2^{\circ} \times 2.5^{\circ}$ & $\mathrm{T} 511\left(\sim 0.35^{\circ} \times 0.35^{\circ}\right)$ \\
\hline Vertical resolution & $\begin{array}{l}26 \text { levels (climate), } 30 \text { levels (forecast), } \\
60 \text { levels (forecast) }\end{array}$ & 30 levels & 24 levels & 60 levels \\
\hline $\begin{array}{l}\text { Number of levels in the } \\
\text { lowest } 1.5 \mathrm{~km}\end{array}$ & $\begin{array}{l}4 \text { (26-level resolution), } 7 \text { (30-level resolution), } \\
12 \text { (60-level resolution) }\end{array}$ & 7 & 8 & 12 \\
\hline
\end{tabular}

at two vertical resolutions: 30 and 60 levels. The 26-level configuration is the standard CAM vertical resolution for conducting global climate simulations. This configuration produces state-of-the-art climate simulations (Boville et al. 2006; Hack et al. 2006; Collins et al. 2006). This is not the case for the 30-level and 60-level versions of CAM because the parameterizations are sensitive to the vertical resolution and the climate simulations are degraded at these vertical resolutions. For instance, a 30-level configuration produces too much low-level cloud and large biases in the shortwave cloud forcing, especially at the surface. However, the processes involved in the generation of these climatological errors include longer time scales than in the forecasts we consider here and they do not adversely affect the shortterm forecasts. This implies that it is possible to use vertical resolutions of 30 or 60 levels for the forecast experiments, and therefore to increase the number of levels in the PBL to match the vertical resolution of CAM-UW and ECWMF model. Here, we show the 30-level forecasts for CAM unless stated otherwise.

\section{b. Observations, analyses, and model climatologies at the EPIC point $\left(20^{\circ} \mathrm{S}, 85^{\circ} \mathrm{W}\right)$}

In this study, we focus on an atmospheric column located at $20^{\circ} \mathrm{S}, 85^{\circ} \mathrm{W}$ in a region of persistent stratocumulus of the southeast Pacific approximately $700 \mathrm{~km}$ off the Peruvian-Chilean border (see Fig. 1). This location is referred to hereafter as the "EPIC point" or the "EPIC column." We employ the set of observations from the 2001 EPIC cruise to assess the forecasts. This cruise provides a comprehensive dataset of remote sensing and surface measurements at the EPIC point for the period 16-21 October 2001 (Bretherton et al. 2004; Caldwell et al. 2005). Profiles of temperature and moisture were obtained from 3-hourly radiosonde observations. Surface sensible and latent heat fluxes were derived from temperature and humidity measurements taken on the ship instrumented tower using the bulk algorithm described by Fairall et al. (1996). The LWP was derived from microwave radiometer brightness temperature measurements (Zuidema et al. 2005). The surface shortwave and longwave downwelling fluxes were obtained from shipboard radiometers. Profiles of liquid water were estimated by assuming that liquid water content increases linearly from a cloud-base value of zero to a cloud-top value such that the integral of liquid water over the PBL matches the observed liquid water path (Caldwell et al. 2005). The 6-day observation period from the EPIC cruise is extensively discussed in Bretherton et al. (2004).

In this section, we evaluate how well the models used here represent the features of the PBL and cloud layer at the EPIC point by comparing ECWMF analyses and AM, CAM, and CAM-UW climatologies with the EPIC cruise observations. Bretherton et al. (2004) indicated that the 6-day period was representative of typical October conditions in this area. In particular, we suggest there is good agreement between the PBL measured during the 2001 cruise and other estimations of the October PBL depth at the EPIC point. The diurnal average of the PBL depth at the EPIC point during the 2001 cruise was $1270 \mathrm{~m}$. Wood and Bretherton (2004) estimated a PBL depth of $1140 \pm 100 \mathrm{~m}$ for September-October 2000 using observed SSTs from the Tropical Rainfall Measuring Mission (TRMM) and cloud-top temperatures from the Moderate Resolution Imaging Spectroradiometer (MODIS). Ahlgrimm and Randall (2006) derived a mean PBL depth of $1450 \mathrm{~m}$ from satellite-based Geoscience Laser Altimeter (GLAS) for October 2003. Since the agreement between the satellite-derived PBL depths and

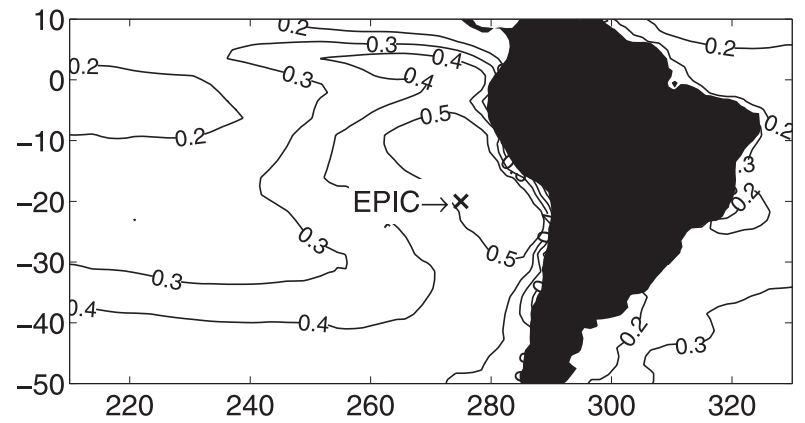

FIG. 1. The EPIC point $\left(20^{\circ} \mathrm{S}, 85^{\circ} \mathrm{W}\right)$ is located in a region of persistent stratocumulus off the coast of South America. The contours are the annual low-level clouds from the International Satellite Cloud Climatology Project (ISCCP; Rossow and Schiffer 1999). Contour increment of cloud fraction is 0.1 . 

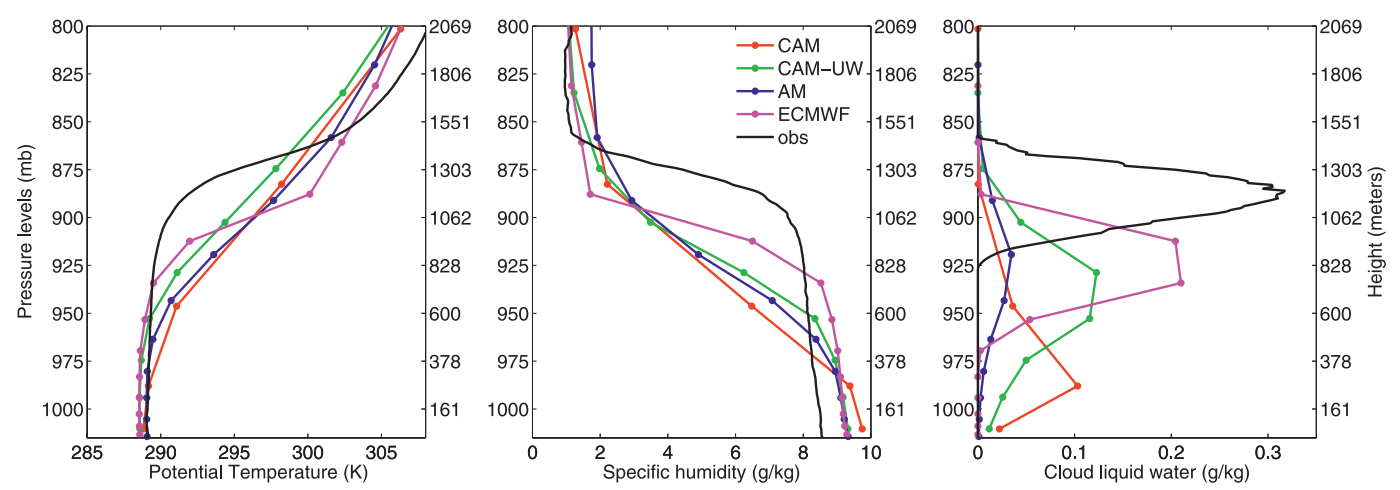

FIG. 2. Comparison of the 6-day mean observed potential temperature, specific humidity, and cloud liquid water profiles from EPIC observations with the mean from the ECMWF analysis created by cycle 29r1 for the same period and location and with October climatological profiles interpolated at the EPIC point for CAM, CAM-UW, and AM.

the PBL measured during the cruise is good, it suggests that a comparison of October climatologies with the 6-day averaged observations at the EPIC point is relevant to indicate the model climate biases.

Figure 2 compares the 6-day mean observed profiles of potential temperature, water vapor, and cloud liquid water with the mean from the ECMWF analysis for the same period and with October climatologies from the three climate GCMs. The observations at EPIC reveal a well-mixed boundary layer under a marked inversion capped by a shallow cloud layer. The ECWMF analysis qualitatively reproduces the main features of the temperature, humidity, and cloud water profiles. However, the ECMWF-analyzed PBL is too shallow by about $250 \mathrm{~m}$ and too moist by $1 \mathrm{~g} \mathrm{~kg}^{-1}$. The three climate GCMs substantially underestimate the PBL depth suggesting an underestimate of entrainment. Their inversion is not well represented, partly because of the poor vertical resolution. This is especially the case for CAM, which has only 4 levels in the lowest $1.5 \mathrm{~km}$, as shown in Table 2 . The three climate GCMs also underestimate cloud liquid water, particularly in the AM. The CAM places the cloud very close to the surface. It is worth noting that while the CAM and CAM-UW parameterizations differ only in the PBL/shallow convective scheme (see Table 1), the CAM-UW sees a significant improvement in the representation of the PBL and cloud layer at the EPIC point compared to CAM. This shows the value of the new PBL scheme in the treatment of marine stratocumulus. However, the CAM-UW boundary layer is still too shallow compared to the EPIC observations, which Park and Bretherton (2009) argue is due to underentrainment. While it is possible to modify the CAM-UW to increase the entrainment and deepen the PBL, this also tends to increase surface evaporation and would lead to an overly strong tropical Hadley circulation. Thus, changes that improve the vertical structure of the stratocumulus in CAM-UW can worsen the overall simulation and should be considered in a global sense.

\section{c. Forecast runs}

The numerical weather prediction (NWP) centers have traditionally compared short model forecasts to observations and analyses to examine process errors associated with the model formulation. Recently climate models have adopted a similar strategy even though they do not necessarily have an analysis system associated with them to generate initial conditions. Phillips et al. (2004) describe a forecast approach for climate models and demonstrate that forecasts made by climate models initialized from NWP analyses or reanalyzes can be useful for examining climate model properties. There are two behaviors in the early period of forecasts to consider: relatively high-frequency noise introduced by dynamical imbalances in the initial data, and an adjustment from the analyzed initial state to states preferred by the model but different from subsequent analyzed states. Modern analysis methods such as that used by the ECMWF provide well-balanced initial conditions, which lead to noise-free forecasts with the analysis model. With a carefully designed interpolation procedure, which takes into account differences in the vertical coordinate system introduced by modeldependent discretization of the orography, a much coarser climate model can also produce relatively noisefree forecasts from such interpolated analyses. We will consider this further when discussing the vertical velocity in the forecasts.

When a climate model is started from NWP analyses, it usually adjusts or transitions from the analyzed atmospheric state to the model preferred state. This adjustment is sometimes referred as the model "spinup." Phillips et al. (2004) argue that if the analyses were perfect, this transition could be attributed to model errors. 
If the dynamical state of the forecast remains close to that of the analysis, the forecast errors are predominantly due to deficiencies in the model parameterizations. Study of this transition and comparison with field campaign observations should provide insight into the parameterization errors. Study of the balances in the model after the transition has occurred is also informative; however, cause and effect is more difficult to untangle. The analyses, however, are not perfect and the transition may be affected by analysis errors. These analysis errors in turn are often introduced by the NWP model, which provides the background field for the analysis. In regions of sparse observations, the NWP model produces background fields that dominate the analysis, especially in variables strongly influenced by the parameterizations. Williamson et al. (2005) discuss a situation in which the climate model adjustment is smaller than it would be from the true atmospheric state because the errors in the initial analyses associated with the analysis model are similar to the errors caused by the climate model. Willet et al. (2008) show the opposite behavior in which the adjustment is exaggerated because of biases in the analyses. These two examples demonstrate that one must always take into account how analyses errors might affect the model transition being studied. This will be discussed further in the following.

In this study, the forecasts are initialized from the ECWMF analysis created by cycle 29r1. This state-ofthe-art analysis uses the parameterizations described in Table 1. One caveat of the analysis and thus the initial conditions is that the PBL is too shallow compared to observations, as shown in Fig. 2. However, this bias is significantly worse in other analyses that we might have used as initial conditions, such as ERA-40 (Uppala et al. 2005), the National Centers for Environmental Prediction (NCEP) operational analysis, or the Japanese 25-yr reanalysis (Onogi et al. 2007). At the moment, the ECWMF analysis cycle 29r1 is the most accurate dataset from which to initialize the forecasts for this location. The initial data include the temperature, specific humidity, horizontal winds, and surface pressure fields. These fields are interpolated to each model's native grid. The SSTs are specified from observed monthly averaged values. Values at each model time step are obtained by linear interpolation from specified midmonth values. The specified values have been adjusted so that the monthly averages from the model are equal to the observed monthly averages (Taylor et al. 2000; Hurrell et al. 2008). There is no diurnal cycle in the specified SST field.

Forecasts are started every day at 1200 UTC for the period 11-22 October 2001 and run for a 3-day period for the ECWMF model and for a 5-day period for CAM,
CAM-UW, and AM. These time periods have been chosen to allow each model to complete its primary adjustment. The forecast data are saved hourly with instantaneous values for state variables and time-average values for fluxes and forcing terms. The CAM, CAM-UW, and $\mathrm{AM}$ forecasts are interpolated to the EPIC point using a distance-weighted average from the four closest model grid points, while the ECMWF forecasts save the closest model point $\left(19.84^{\circ} \mathrm{S}, 84.96^{\circ} \mathrm{W}\right)$. Using a weighted average versus looking at the closest model column gives qualitatively similar results for most variables. In particular, the four model grid points bracketing the EPIC point in the climate GCMs show a relatively homogeneous behavior, while averaging the ECWMF forecasts over a domain size comparable to the climate GCMs grid box gives results qualitatively similar to extracting the closest column output.

To reduce the sampling noise and to better show forecast systematic errors, we examine the average over the forecasts at fixed elapsed times as illustrated in Fig. 3. We refer to this average as the "ensemble mean forecast." In the next section, we first examine the evolution of the 5-day ensemble mean forecast (3-day for the ECWMF model) and the transition from the initial state to the model preferred states. Then, for each model, we focus on the time period of the forecast after the model completes its primary adjustment.

\section{Forecasts at the EPIC point}

\section{a. Vertical structure and departure from the initial state in the forecasts}

We examine how the vertical structure of the lower troposphere evolves in the forecasts during the departure from the initial state. Figure 4 shows the instantaneous vertical profiles of the ensemble mean forecast specific humidity and liquid water potential temperature as a function of the forecast time. The forecasts at day 0 correspond to the initial condition from the ECWMF analysis interpolated to the model grid. The ECWMF model shows a well-mixed PBL and preserves the moisture and liquid water potential temperature characteristics throughout the 3-day forecasts. Since the EPIC region had few observations to define the vertical structure of the PBL in the analyses (in particular, the EPIC cruise observations were not used in the ECMWF analyses), the vertical structure in the initial conditions is largely determined by the ECMWF model parameterizations. Therefore it is not surprising that the ECMWF forecasts show little adjustment during the forecasts. In CAM, the PBL top (defined here as the base of the inversion in specific humidity) rapidly collapses from about 800 to $400 \mathrm{~m}$ within three days of forecasts, 


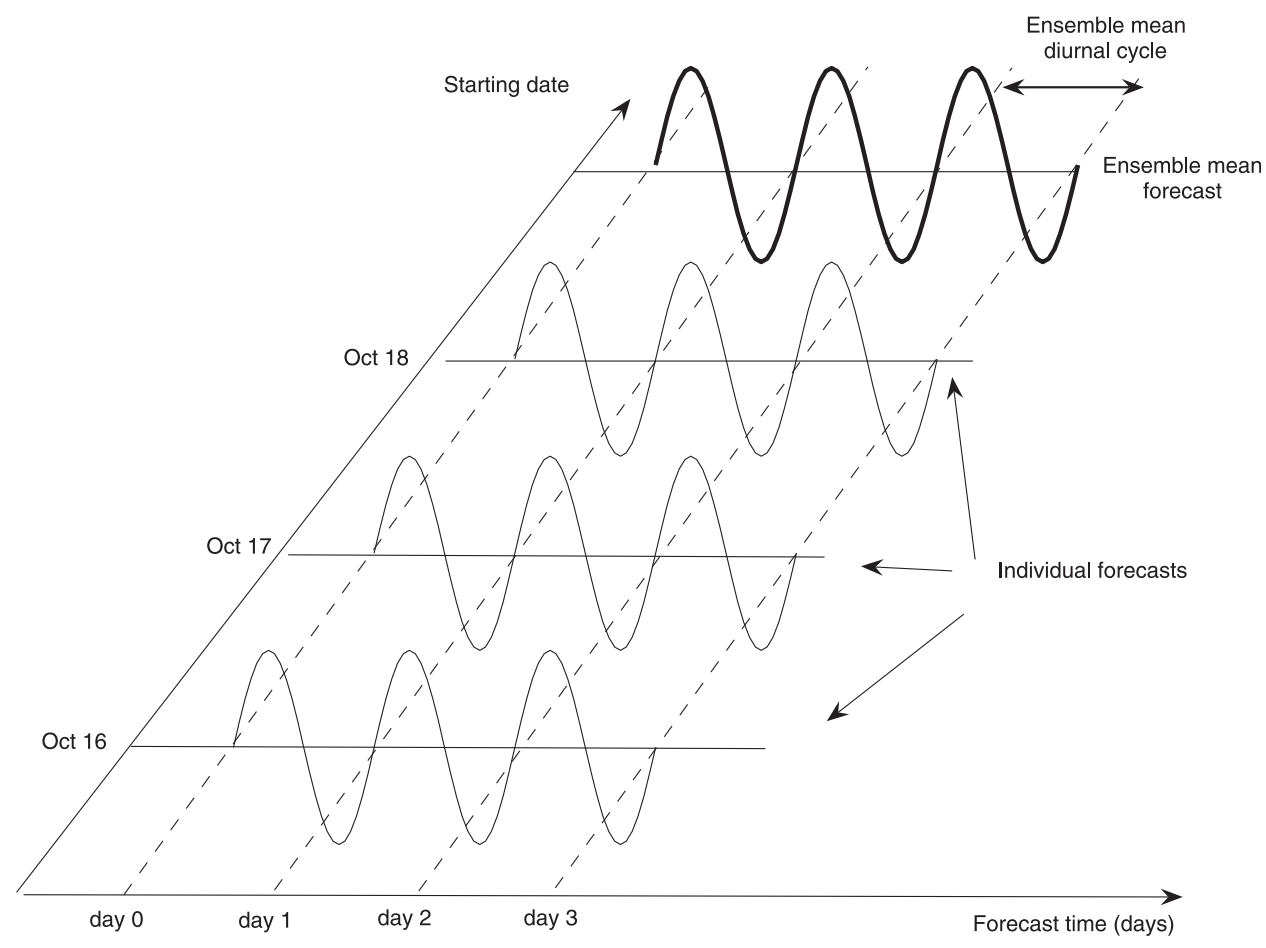

FIG. 3. Ensemble mean forecast (bold line) taken along the dashed line.

revealing the inability of the model physics to maintain a well-mixed PBL and a sharp inversion. The CAM-UW also shows a shallowing of the PBL, but it is significantly less pronounced than in CAM. This suggests that the CAM-UW physics is superior to CAM for representing stratocumulus-topped PBLs. The PBL height of cloudtopped boundary layers is controlled by two competing processes: the large-scale subsidence that pushes down the PBL and the entrainment of warm and dry air from aloft that constantly lifts the PBL top, maintaining it against the large-scale subsidence. It is instructive to examine how the CAM and CAM-UW represents these two competing processes. The two models treat the entrainment differently. In CAM, the entrainment is an implicit consequence of the model's mixing scheme while in CAM-UW the cloud-top entrainment is explicitly computed. The two models show similar patterns of vertical velocity (as discussed later in conjunction with Fig. 8). This suggests that the CAM-UW is able to produce a deeper and better-mixed PBL because of the explicit entrainment closure of its PBL scheme. To illustrate the differences between the two models, we examine the relevant terms in the moisture equation in Fig. 5. In CAM, the PBL scheme moistens levels around $950 \mathrm{mb}$. This moist layer triggers the shallow convection scheme, which ventilates the moisture higher in the atmosphere to about $925 \mathrm{mb}$. In CAM-UW, the PBL scheme directly moves the moisture to $925 \mathrm{mb}$ without any significant contribution from the shallow convective scheme.

As with CAM and CAM-UW, the AM shows a shallowing of the PBL during the 5-day forecast in Fig. 4. The AM maintains the PBL depth better than CAM, possibly because of its formulation of radiatively driven entrainment rates for cloud-topped boundary layers. The AM transition is not as monotonic as those from CAM and CAM-UW. This behavior might arise from noise in the AM forecast, which will be illustrated further in the vertical velocity. Note that the time scale in which the PBL height adjusts in the forecasts is consistent with Schubert et al. (1979), who demonstrated with a mixed-layer model of stratocumulus that the adjustment time scale of the PBL height is on the order of several days.

In Fig. 4, we also examine how the forecasts compare with climatological runs. We show mean October climatologies at the EPIC point for the three climate GCMs. A climatology is not available for the version of the ECWMF model used here for forecasts. At this location, the GCM forecast biases develops very quickly. Within 5 days of forecast, the temperature and moisture in CAM and in CAM-UW have regressed close to their own climatologies. That is only partly true for AM. The full climate error develops on a longer time scale with additional slower processes that come into play, but the forecast error qualitatively reproduces the climatological 

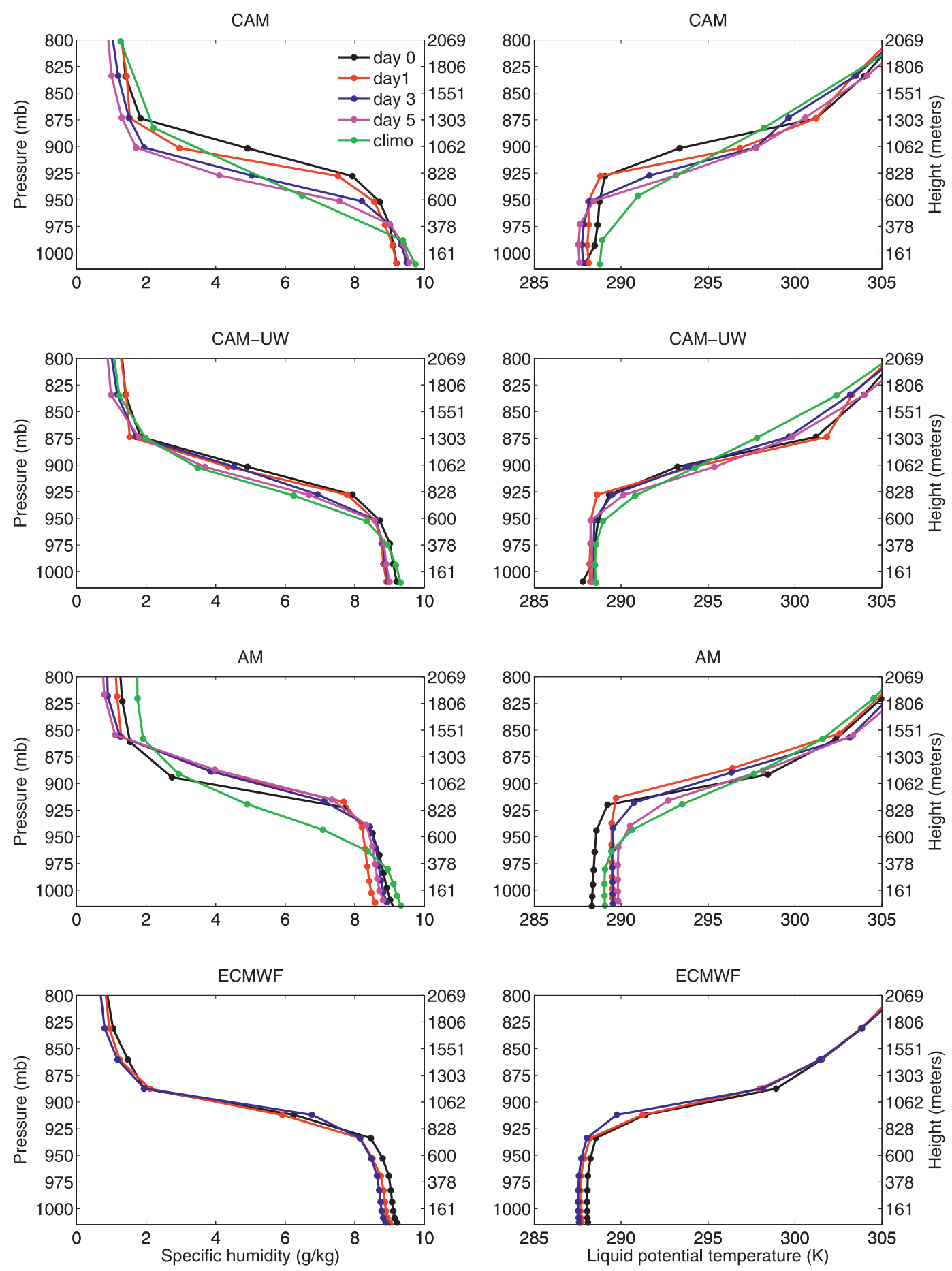

FIG. 4. Ensemble mean forecast and climatology of (left) specific humidity and (right) liquid water potential temperature for CAM, CAM-UW, AM, and ECMWF. Instantaneous values of the mean forecast at day $0,1,3$, and 5 (black, red, blue, cyan) and mean October climate when available (green) are shown. Notice that the forecasts for CAM are on 30 levels and the climatology is on 26 levels for the reasons developed in section 2a. 

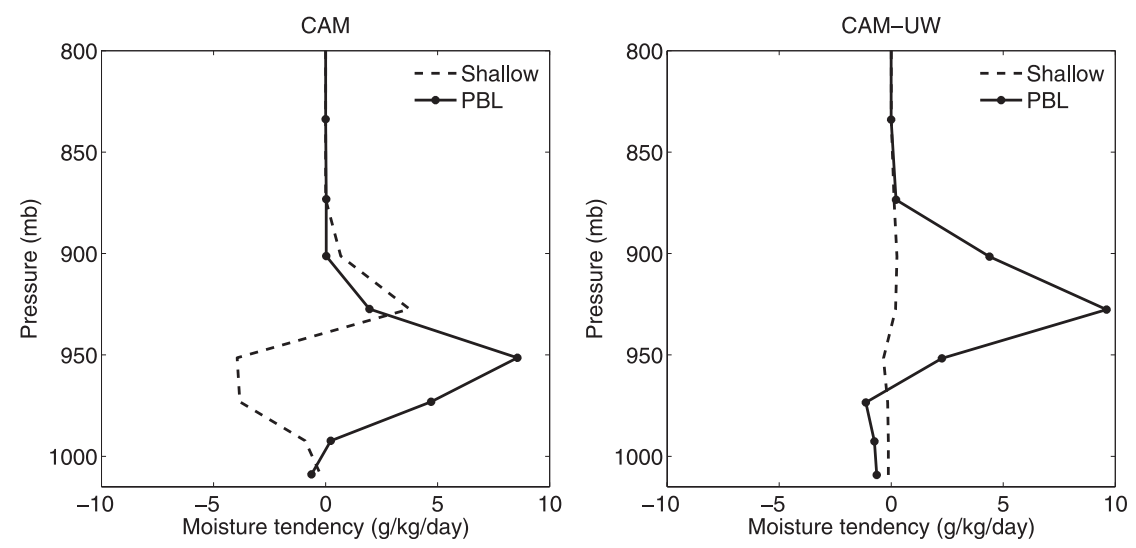

FIG. 5. Moisture tendencies coming from the PBL scheme and the shallow convection scheme for CAM and CAM-UW.

biases. This indicates that the utility of using short-range forecasts to study climate model biases.

We believe that the initialization errors do not affect the model transitions being studied in Fig. 4. As pointed out earlier, the vertical structure in the initial conditions is largely determined by the ECMWF model parameterizations because of the scarcity of observations in this region to constrain the analysis. In particular, we showed in Fig. 2 that the PBL is shallower in the ECMWF analysis than indicated by the EPIC observations. Since the three climate models lower the PBL even further to some degree, we suggest that the climate model adjustments are not caused by the error in the initial PBL height.

We showed in Table 2 that the models have a wide range in vertical resolution (from 24 vertical levels for AM to 60 levels for the ECWMF model). Previous studies demonstrate that an enhancement of the vertical resolution in the boundary layer can lead to improvements in the vertical structure of the cloud-topped boundary layer produced by GCMs in both well-mixed and decoupled situations (e.g., Bushell and Martin 1999; Pope et al. 2001). Stevens et al. (2007) show that, despite an enhanced vertical resolution in the ERA-40 compared to the ERA-15, the PBL depth is underestimated in both reanalyzes, suggesting that the overly shallow PBL is not simply due to insufficient vertical resolution. We investigate the impact of increased vertical resolution on the PBL depth and in particular whether a vertical resolution comparable to the ECMWF model can help to maintain the PBL depth in the CAM forecasts. Figure 6 shows the CAM forecast specific humidity as a function of forecast time with a 60-level vertical resolution. Increasing the vertical resolution from 30 to 60 levels has little impact on the PBL depth. At both resolutions, the PBL rapidly collapses from about 800 to $400 \mathrm{~m}$ within 3 days into the forecast.
Figure 7 shows the evolution of the cloud field in the 5-day ensemble mean forecast (3 day for ECMWF forecasts). Because there is a strong diurnal cycle of the cloud structure, we use daily averages of the ensemble mean forecast instead of instantaneous values. In CAM, the level of maximum cloud fraction and cloud water descends from about 925 to $950 \mathrm{mb}$ as can be expected from the collapse of its PBL. The other models maintain the level of maximum cloud fraction and cloud water at their initial levels. In the climate GCMs, the cloud fraction and amount of cloud water typically decrease in the 5-day forecasts. Again, the climatological error in AM develops on longer time scale, as to a lesser extent do CAM and CAM-UW. Data from the EPIC cruise show that the cloud layer is located at the top of the mixed layer. In the CAM, CAM-UW and AM, the cloud layer is more centered on the model inversion, rather than at the top of the PBL. This is because the three climate GCMs produce too-shallow mixed layers. The ECWMF model produces more realistic results and places the maximum of liquid cloud layer close to the bottom of the inversion layer. This represents a significant improvement compared to the ERA-40 and the earlier versions of the ECMWF Integrated Forecast System (IFS) that did not include the Köhler (2005) PBL scheme. Stevens et al. (2007) showed that, without the Köhler scheme, the ECMWF model suffers the same limitations as the CAM, CAM-UW, and AM: lower PBL and cloud located above the mixed layer. It is interesting to point out that CAM sometimes produces clouds with little or no cloud water, which are referred to as "empty clouds." The empty clouds are particularly obvious in the first day forecast: at $900 \mathrm{mb}$, CAM predicts a cloud fraction equal to 0.3 despite having no cloud water at this level. This inconsistency comes from the fact that the diagnostic cloud fraction is 

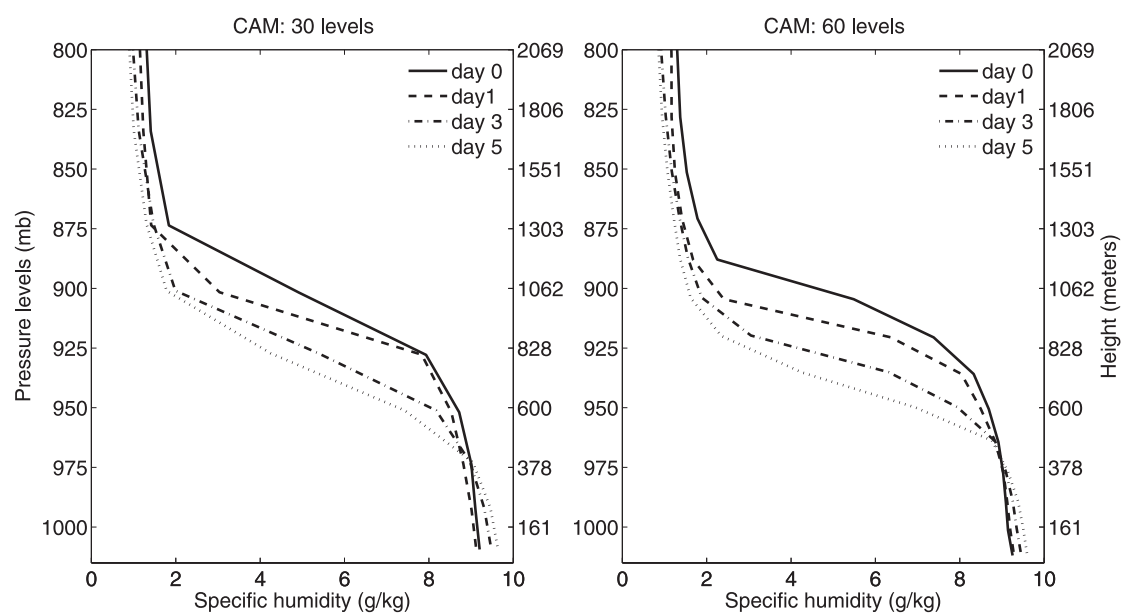

FIG. 6. Ensemble mean forecast specific humidity for CAM at 30 levels and 60 levels.

computed independently from the prognostic cloud water in CAM. In particular, the CAM computes a cloud fraction related to the updraft mass flux in the shallow cumulus scheme according to a functional form suggested by $\mathrm{Xu}$ and Krueger (1991). Since the shallow convection scheme is active in CAM at the EPIC column as illustrated in Fig. 5, the model produces a convective mass flux and computes a cloud fraction related to this mass flux. This results in empty clouds in the layers where the shallow scheme is active. This is also another difference between CAM and CAM-UW: the latter does not produce empty clouds at EPIC because the shallow convection does not have a significant contribution in CAM-UW at EPIC as shown in Fig. 5.

The ensemble mean forecast of vertical pressure velocity $\omega$ is shown in Fig. 8. In the present section, we concentrate on the noise and general characteristics of $\omega$. The diurnal cycle of $\omega$ will be discussed in the next section. The vertical pressure velocity is particularly sensitive to the initial conditions, and dynamical imbalances in the initial data can introduce high-frequency noise in $\omega$. The ECMWF vertical velocity does not have such a noise because the model is initialized with its own analysis and therefore has well-balanced initial conditions. The CAM and CAM-UW show small-amplitude, high-frequency oscillation in the vertical motion during the first $6 \mathrm{~h}$ of the forecast. This is probably due to small dynamical imbalances in the interpolated initial conditions, but it is rapidly suppressed and appears not to affect the general transition of the vertical motion to the model preferred behavior. The AM shows more noise arising from the interpolation to the model grid in the early part of the forecasts, but there is no indication of the noise after day 4 . Figure 8 also shows that the large-scale state does not diverge too far from the initial analysis within 5 days of forecast. In CAM and CAMUW, the diurnal cycle of the vertical velocity looks very similar during day 1 and day 5 (except for slight noise during day 1). This shows that the model dynamical state after 5 days of forecasts does not differ much from its initial state. After the noise has settled down in AM (i.e., at day 4 and after), the vertical velocity in AM is rather similar to that of CAM. This suggests similar large-scale flows in the two models. Since the dynamical state of the forecast remains close to the initial state, we can assume that the forecast errors are predominantly due to deficiencies in the model parameterizations.

\section{b. The diurnal cycle of LWP and the surface energy balance at EPIC}

During the EPIC cruise, the stratocumulus cloud layer exhibits a marked and regular diurnal cycle. Because stratocumulus clouds influence the radiation budget primarily through their reflection of solar radiation, their diurnal cycle has an important influence on their radiative effectiveness. Rozendaal et al. (1995) estimated that the exclusion of the diurnal cycle of low-level cloud fraction in radiation calculations causes an overestimate in surface total cloud forcing of about $3 \mathrm{~W} \mathrm{~m}^{-2}$. Therefore, a realistic representation of the diurnal cycle is crucial to achieve an accurate energy balance at the surface. This is especially important in coupled simulations as a misrepresentation of the net flux between the atmosphere and ocean can lead to severe SST biases.

The EPIC cruise provides an opportunity for testing the ability of the models to simulate the diurnal cycle in stratocumulus regions since it effectively sampled multiple diurnal cycles in a marine stratocumulus environment. Because of the regularity of the diurnal cycle 

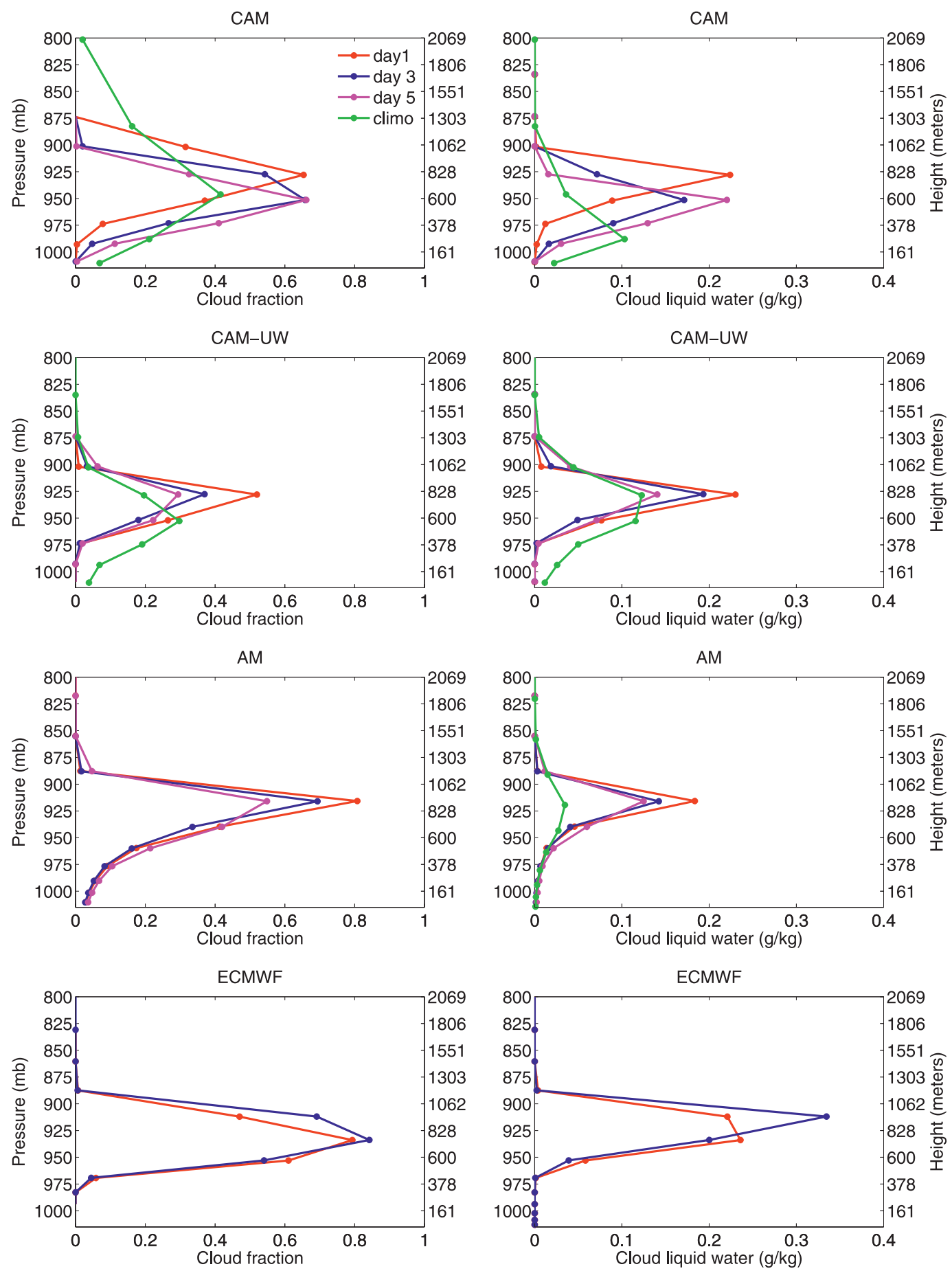

FIG. 7. Ensemble mean forecast and climatology of (left) cloud fraction and (right) cloud liquid water for CAM, CAM-UW, AM, and ECMWF. Mean forecast at day 0 and mean forecast averaged over day 1, 3, and 5 (black, red, blue, cyan) and mean October climate when available (green) are shown.

during the cruise, this dataset is particularly well suited to evaluate the mean ensemble forecast against a mean diurnal cycle. In Fig. 9, we examine the diurnal cycle of LWP and its impact on the surface energy balance. (For reference, the daily averages are also shown Table 3). The surface energy balance can be written

$$
\text { Net flux }=\mathrm{SW}+\mathrm{LW}+\mathrm{SH}+\mathrm{LH},
$$



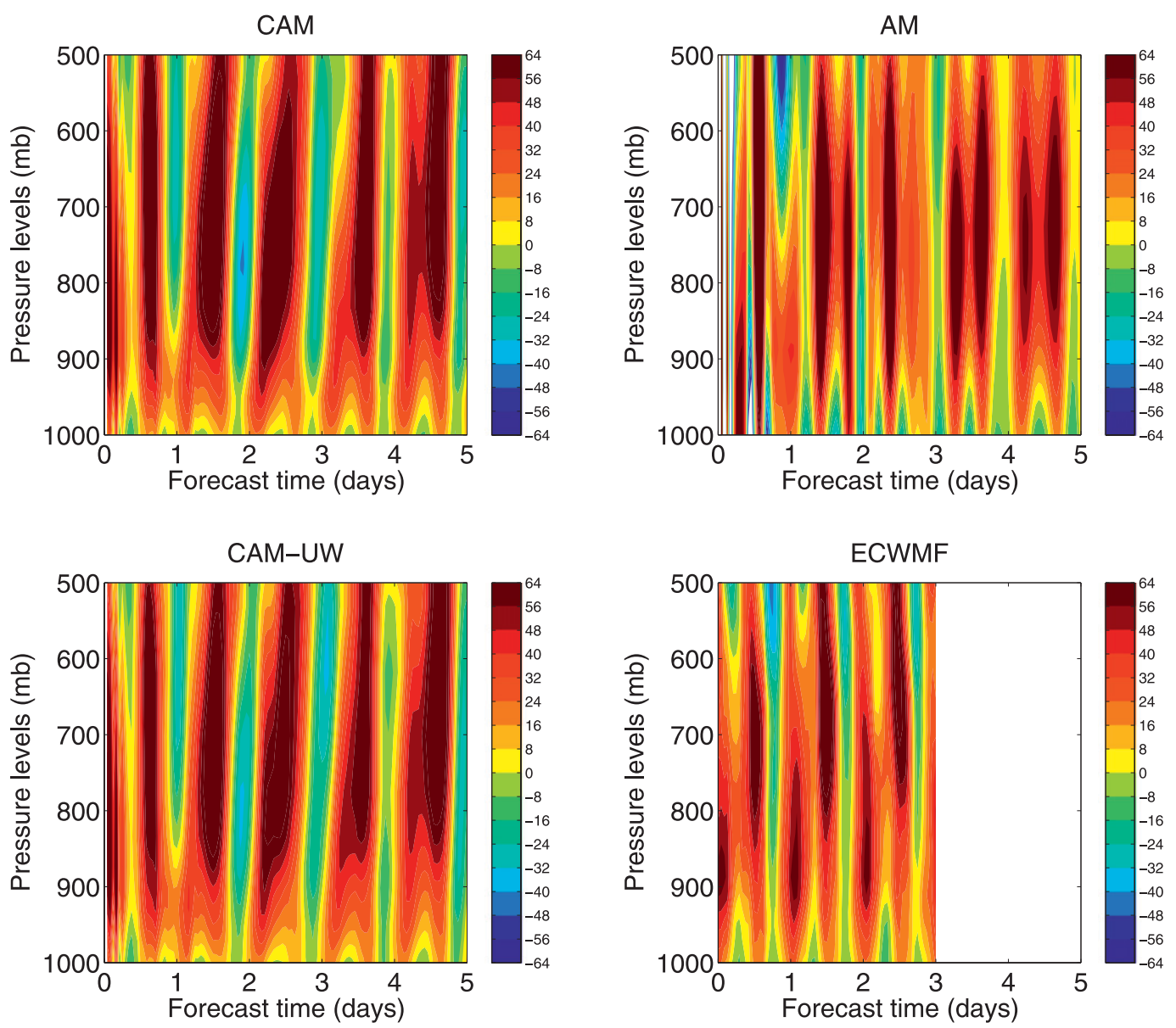

FIG. 8. Ensemble mean forecast of vertical pressure velocity $\left(\mathrm{mb} \mathrm{day}^{-1}\right)$ for CAM, CAM-UW, AM, and the ECMWF model.

where SW and LW are the net shortwave and longwave radiative fluxes at the surface and $\mathrm{SH}$ and $\mathrm{LH}$ are the sensible and latent heat fluxes between the ocean surface and the atmosphere, respectively. The sign convention is that fluxes are positive when directed into the atmosphere. We also show other diagnostic variables relevant to our discussion: effective droplet radius, vertical velocity at $850 \mathrm{mb}$, and surface wind.

Before discussing the diurnal cycle of each variable, let us point out that we examine the diurnal cycle of the ensemble mean forecast after the models have achieved their initial transition. For the ECWMF model, we look at the third day of forecast (hour 48-72) even though its transition is minimal. For CAM, CAM-UW, and AM, we focus on results from the fifth day of forecast (hour 96-120). At that stage the PBL has shallowed significantly and a large component of the forecast error has developed, but the large-scale state has not yet diverged too far from the observations, as discussed earlier. Since the dynamical state of the forecast remains close to the initial state, we can assume that the forecast errors are predominantly due to deficiencies in the model parameterizations.

First, we determine how well the models represent LWP. The mean LWP during the 6-day observation period is $106 \mathrm{~g} \mathrm{~m}^{-2}$. The LWP had a strong and regular diurnal cycle during the 6-day period (Zuidema et al. 2005). The diurnal cycle of the LWP dominates the total variability: the range of the diurnal cycle of the LWP is around $150 \mathrm{~g} \mathrm{~m}^{-2}$ and it largely exceeds the day-to-day variation. At night, the strong longwave cooling near the top of the cloud creates turbulence and produces a well-mixed PBL. This leads to the transport of moisture from the surface. The LWP increases and reaches a maximum in early morning, around 3:00 a.m. local solar time (0300 LST). The LWP decreases after sunrise as the shortwave heating of the cloud increases and counteracts the longwave cooling. Because of this compensating effect, the turbulence decreases and this leads to a decoupling between the cloud and the surface accompanied 

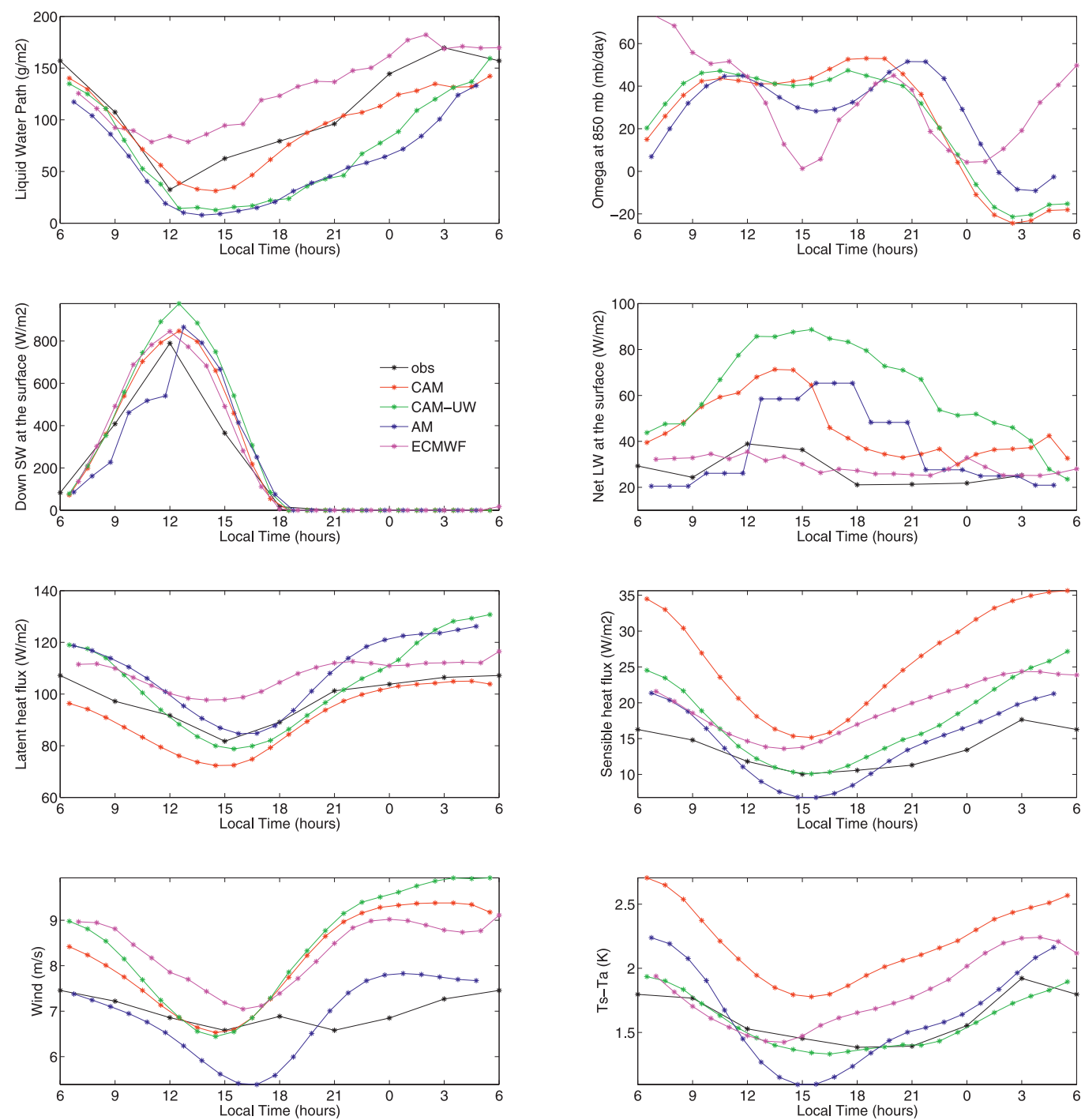

FIG. 9. Diurnal cycle of the ensemble mean forecast of the LWP, downwelling shortwave radiation, net longwave radiation, latent heat flux, sensible heat flux, vertical velocity at $850 \mathrm{mb}, 10-\mathrm{m}$ wind, and temperature difference between the surface and the 2-m level.

by a thinning of the cloud layer. The LWP reaches a minimum in early afternoon, around 1300 LST. It is interesting to notice that the minimum LWP during the 2001 cruise occurs a bit earlier than observed in other stratocumulus studies: satellite data and surface observations of stratocumulus have shown a minimum LWP occurring around 1500 LST (Rozendaal et al. 1995; Wood et al. 2002; Duynkerke et al. 2004). All the models capture a strong diurnal cycle in LWP but there are some differences in the daily mean, amplitude, and phase of the cycle. The ECWMF model overestimates the daily mean LWP, but it reproduces fairly well the phase and the range of the diurnal cycle. The good agreement with the observed diurnal cycle is likely due to the eddy-diffusivity/mass-flux scheme that was incorporated in the ECWMF model. Köhler (2005) showed that the new PBL scheme significantly improves the magnitude and diurnal cycle of LWP at the EPIC point compared to a dry PBL approach as used in the ERA-40 (see their Fig. 5). Stevens et al. (2007) indicate that similar improvements are evident in other marine stratocumulus regions, such as in the Californian stratocumulus during the DYCOMS II experiment. The main origins of this improvement in the ECWMF model were traced to a more well-mixed PBL and a higher PBL top (Köhler 2005). The three climate GCMs underestimate the daily mean of LWP compared to observed values. The deficit is very severe in the AM model, which has a 
TABLE 3. Daily average of the LWP, effective radius, and the surface energy budget terms and the wind at reference level and vertical pressure velocity at 850 mbar. The numbers in parentheses show typical errors in the daily estimates of observed values [see Zuidema et al. (2005) for LWP and Colbo (2005) for the surface fluxes]. The lower value of the observed effective radius was estimated assuming an adiabatic cloud layer and the larger value from MODIS. The observed net shortwave radiation was computed from the downwelling component assuming a surface albedo equal to 0.05 . The reference wind corresponds to the wind at $10 \mathrm{~m}$ for the observations, AM, and the ECWMF model and to the wind on the first model level for CAM and CAM-UW.

\begin{tabular}{|c|c|c|c|c|c|}
\hline & Observations & CAM & CAM-UW & $\mathrm{AM}$ & ECMWF \\
\hline $\operatorname{LWP}\left(\mathrm{g} \mathrm{m}^{-2}\right)$ & $106(6)$ & 92 & 73 & 61 & 131 \\
\hline $\operatorname{Re}$ (microns) & $13-15$ & 14 & 14 & 6.7 & 12.4 \\
\hline Net SW $\left(\mathrm{W} \mathrm{m}^{-2}\right)$ & $-208(4)$ & -228 & -238 & -199 & -214 \\
\hline Net LW $\left(\mathrm{W} \mathrm{m}^{-2}\right)$ & $28(6)$ & 46 & 58 & 36 & 29 \\
\hline Latent heat $\left(\mathrm{W} \mathrm{m}^{-2}\right)$ & $98(5)$ & 92 & 104 & 107 & 107 \\
\hline Sensible heat $\left(\mathrm{W} \mathrm{m}^{-2}\right)$ & $14(1.5)$ & 26 & 18 & 14 & 19 \\
\hline Net flux $\left(\mathrm{W} \mathrm{m}^{-2}\right)$ & $-68(8)$ & -64 & -58 & -42 & -59 \\
\hline Reference wind $\left(\mathrm{m} \mathrm{s}^{-1}\right)$ & 8.0 & 8.2 & 8.4 & 7.4 & 8.3 \\
\hline$\omega 850 \mathrm{mb}\left(\mathrm{mb} \mathrm{day}^{-1}\right)$ & - & 21 & 21 & 28 & 30 \\
\hline
\end{tabular}

mean value of $61 \mathrm{~g} \mathrm{~m}^{-2}$. This may reflect that the entrainment across the strong inversions at the top of the boundary layer is not well represented in AM (GFDL Global Atmospheric Model Development Team 2004). In CAM, the LWP reaches its minimum later than observations (around 1400 LST) and is underestimated in the afternoon and in the early morning. In the CAMUW and AM, the LWP falls close to zero in the late afternoon (1600 LST). The AM significantly underestimates the LWP during the night also. The spread in LWP in part reflects the sensitivity of cloud liquid water to the changes in total humidity and temperature induced by the different PBL and microphysics schemes. It should be pointed out that CAM and CAM-UW use the same cloud microphysics and yet produce significant differences in LWPs, indicating that the different turbulent transport is a more important factor than the microphysics for causing the differences in LWP in this case. The CAM-UW turbulence scheme interacts tightly with other physical parameterizations, and Park and Bretherton (2009) identified some problems in the cloud macrophysics that can significantly affect the LWP in the CAM-UW. While both CAM and CAM-UW are influenced by the shortcomings in the current cloud macrophysics, CAM-UW is more sensitive to these problems because CAM-UW explicitly treats the "cloudradiation-turbulence" interactions while CAM does not.

While the LWP determines to first order the cloud radiative impact, the microphysical properties of clouds such as the effective radius ( $\mathrm{Re}$ ) also influence the cloud radiative properties. For a given cloud water content, the underestimation of the effective radius results in a corresponding increase of the optical depth and therefore shortwave cloud reflection. It is relevant to examine how the models represent the effective radius compared to observations. There was no aircraft mea- surement of the effective radius during the EPIC cruise and we estimate Re from satellite- and ship-based measurements (see Table 3 ). The effective radius estimated from MODIS (King et al. 2003; Platnick et al. 2003 ) is about 15 microns at the EPIC point (Wood et al. 2007). A computation of Re assuming an adiabatic layer cloud (R. Wood 2006, personal communication) and using the ship liquid water path with a cloud droplet number concentration of $100 \mathrm{~cm}^{-3}$ (Mechoso et al. $2005)$ gives a value of 13 microns. These two estimates of Re have large uncertainties but are useful to compare with model values. The models use different formulations for the effective radius. The CAM and CAM-UW prescribe a constant effective radius but with different values over ocean and land. Over the ocean, the effective radius is set to 14 microns in CAM and CAM-UW. The AM and the ECWMF model diagnose the effective radius from the predicted liquid water content and an assumed cloud droplet number concentration as described in Martin et al. (1994). The droplet number concentration over the ocean is set to $100 \mathrm{~cm}^{-3}$ in AM and $50 \mathrm{~cm}^{-3}$ in the ECWMF model. The insolation and extinction weighted effective radius is 6.7 microns for AM and 12.4 microns for the ECWMF model. While the CAM, CAM-UW, and ECMWF effective radii are consistent with the observations, the AM effective radius is low compared to observations.

The errors in LWP and effective radius affect the radiative fluxes at the surface. The scatter in LWP between models is reflected both in the shortwave and longwave: the clouds tend to reduce the downward solar radiation and to a lesser extent the net longwave radiation at the surface. All the models tend to overestimate the amount in downwelling shortwave reaching the surface in the afternoon. This is especially the case for CAM-UW and AM which overestimate the shortwave 
during the late afternoon when their LWPs drop close to zero. For the same reasons, these two models show large values of the net longwave at the surface in the afternoon. Despite low values of the LWP, the AM model underestimates the shortwave radiation reaching the surface. This is due to its small values of effective radius. For a given cloud water content, the transmitted shortwave cloud decreases with the size of the effective radius.

The diurnal cycles of the latent and sensible heat fluxes are shown in Fig. 9. The surface fluxes can be estimated through the use of bulk aerodynamic formulas: $\mathrm{SH} \alpha U_{r}\left(T_{s}-T_{a}\right)$ and $\mathrm{LH} \alpha U_{r}\left(q_{s}-q_{a}\right)$, where $U_{r}$ is the mean wind at some standard height (typically $10 \mathrm{~m}$ ); $T$ and $q$ are the temperature and specific humidity, respectively; and the subscripts $s$ and $a$ indicate values for the surface and the air at the reference level, respectively. We also show plots of the 10-m wind and $\left(T_{s}-T_{a}\right)$ in Fig. 9 in order to interpret the results. Diagnostics of $\left(q_{s}-q_{a}\right)$ were not available. Since the 10 -m wind is not available in CAM and CAM-UW, we show values of the wind on the lowest model level for these models. The latent heat flux compares reasonably well with observations. The sensible heat flux shows larger relative errors and its diurnal cycle is too large compared to observations. The error in air temperature strongly affects the sensible heat flux.

The ensemble mean forecast of the pressure vertical velocity is shown in Fig. 8 and its value at $850 \mathrm{mb}$ in Fig. 9. In the ECMWF model, subsidence prevails during most of the day in the middle and lower troposphere. There is upward motion around midnight local solar time (0000 LST). Garreaud and Muñoz (2004) showed that this upward motion was associated with a wave propagating from the Andes. This wave produces significant cooling and leads to a more turbulent PBL and more entrainment. This increases the amplitude of the diurnal cycle of the stratocumulus amount with respect to the cycle forced by radiation absorption only. The upward motion is visible in all the models. In the ECWMF model, it occurs around 0000 LST, as reported by Garreaud and Muñoz (2004). In the CAM, CAMUW, and AM, the upward motion occurs later, around 0300 LST. The ECWMF vertical velocity also has a semidiurnal cycle that affects the whole middle and lower troposphere. This semidiurnal signal is well known in the ERA-40 (Hoinka 2007) and is due to the solar semidiurnal tide, partially because of the stratospheric atmospheric heating (Whiteman and Bian 1996). CAM and CAM-UW show hints of a semidiurnal cycle near the surface, but it does not extend above the PBL. The semidiurnal cycle is also visible in the AM vertical velocity after day 4 when the noise has settled down. The oscillation in the vertical velocity is likely to be a combination of both signals: waves propagating from the Andes and semidiurnal tide.

\section{Conclusions}

Typically GCMs do not represent regions of stratocumulus well. Stratocumulus clouds are often severely underestimated in GCMs and the PBL depth is too shallow compared to observations. Also, because these clouds influence the radiation primarily though their albedo, their diurnal cycle is an important factor on their radiative effectiveness. In this study, we look at these processes using short-term forecasts covering the period of an in situ experiment, the EPIC cruise of October 2001.

We examine two climate models (CAM and AM), one revised PBL scheme (CAM-UW), and one forecast model (ECMWF). A key problem common to all the models is that they produce too-shallow PBLs. The observed PBL is about $1100 \mathrm{~m}$ deep while the models produce PBL depths between 400 and $800 \mathrm{~m}$. However, our results suggest that, as the sophistication of the PBL scheme increases, better PBL heights are achieved. At one end, CAM uses a dry and surface-driven PBL scheme and produces a very shallow PBL. At the other end, the ECWMF model uses an eddy-diffusivity/massflux approach and produces the best results in terms of PBL height and mixing. All the models are able to reproduce a strong diurnal cycle in LWP at the EPIC point, but there are discrepancies in the daily mean, as well as in the magnitude and phase of the diurnal cycle. This reflects in part the sensitivity of cloud water to the changes in humidity and temperature profiles induced by the different PBL and microphysics schemes. The errors in LWP and effective radius affect the radiative fluxes at the surface and, therefore, the surface energy balance. There is a large spread in the components of the energy balance between the models and large discrepancies with observations. This is especially important in coupled simulations as a misrepresentation of the net flux between the atmosphere and ocean can lead to severe SST biases.

This study suggests that significant progress has been made in the parameterization of cloud-topped boundary layers although the sizeable differences between models and observations does suggest that further work is needed. This work also demonstrates the utility of the EPIC case for model validation and serves as a benchmark to measure improvements in future versions of the models.

Acknowledgments. The authors wish to thank Peter Caldwell from the University of Washington for providing 
observational data compiled from a combination of measurements made during the EPIC 2001 stratocumulus field campaign. We are grateful to Paquita Zuidema for providing LWP data and effective radius estimates. We thank Ming Zhao and Sungsu Park for providing the AM and CAM-UW climatological data, respectively. We thank Rich Neale, Anthony Del Genio, and two anonymous reviewers for their constructive comments that helped to substantially improve this manuscript. We acknowledge the support of NSF ATM Grant 0336688 for Cecile Hannay. Chris Bretherton was funded through NSF ATM Grants 0336703 and 0433712. Stephen Klein was funded through the U. S. Department of Energy, Office of Science, Office of Biological and Environmental Research. The contribution of Stephen Klein was performed under the auspices of the U.S. Department of Energy by Lawrence Livermore National Laboratory under Contract DE-AC52-07NA27344. Jerry Olson and David Williamson were partially funded by the Office of Science (BER), U.S. Department of Energy, Cooperative Agreement DE-FC02-97ER62402.

\section{REFERENCES}

Ahlgrimm, M., and D. A. Randall, 2006: Diagnosing monthly mean boundary layer properties from reanalysis data using a bulk boundary layer model. J. Atmos. Sci., 63, 998-1012.

Angevine, W. M., 2005: An integrated turbulence scheme for boundary layers with shallow cumulus applied to pollutant transport. J. Appl. Meteor., 44, 1436-1452.

Bechtold, P., S. K. Krueger, W. S. Lewellen, E. van Meijgaard, C. H. Moeng, D. A. Randall, A. van Ulden, and S. Wang, 1996: Modeling a stratocumulus-topped PBL: Intercomparison among different one-dimensional codes and with large eddy simulation. Bull. Amer. Meteor. Soc., 77, 2033-2042.

Bergman, J. W., and M. L. Salby, 1997: The role of cloud diurnal variations in the time-mean energy budget. J. Climate, 10, $1114-1124$.

Bony, S., and J.-L. Dufresne, 2005: Marine boundary layer clouds at the heart of tropical cloud feedback uncertainties in climate models. Geophys. Res. Lett., 32, L20806, doi:10.1029/ 2005 GL023851.

Boville, B. A., P. J. Rasch, J. J. Hack, and J. R. McCaa, 2006: Representation of clouds and precipitation processes in the Community Atmosphere Model version 3 (CAM3). J. Climate, 19, 2184-2198.

Boyle, J. S., and Coauthors, 2005: Diagnosis of Community Atmospheric Model 2 (CAM2) in numerical weather forecast configuration at Atmospheric Radiation Measurement sites. J. Geophys. Res., 110, D15S15, doi:10.1029/2004JD005042.

—, S. Klein, G. Zhang, S. Xie, and X. Wei, 2008: Climate model forecast experiments for TOGA COARE. Mon. Wea. Rev., 136, 808-842.

Bretherton, C. S., and S. Park, 2009: A new moist turbulence parameterization in the Community Atmosphere Model. J. Climate, in press.

_ and Coauthors, 2004: The EPIC 2001 Stratocumulus Study. Bull. Amer. Meteor. Soc., 85, 967-977.
Bushell, A. C., and G. M. Martin, 1999: The impact of vertical resolution upon GCM simulations of marine stratocumulus. Climate Dyn., 15, 293-318.

Caldwell, P., C. S. Bretherton, and R. Wood, 2005: Mixed-layer budget analysis of the diurnal cycle of entrainment in southeast Pacific stratocumulus. J. Atmos. Sci., 62, 3775-3791.

Colbo, K., 2005: IMET sensor accuracy. Woods Hole Oceanographic Institution Upper Ocean Processes Group Tech. Note, 2 pp. [Available online at http://uop.whoi.edu/techdocs/ technote/TN05_09SensorAccuracy.pdf.]

Collins, W. D., and Coauthors, 2004: Description of the NCAR Community Atmosphere Model (CAM 3.0). National Center for Atmospheric Research Tech. Rep. NCAR/TN-464+STR, $226 \mathrm{pp}$. [Available online at http://www.library.ucar.edu/uhtbin/ cgisirsi/20090203214420/SIRSI/0/520/DR000776.]

— simulation of the Community Atmosphere Model version 3 (CAM3). J. Climate, 19, 2144-2161.

Duynkerke, P. G., and J. Teixeira, 2001: Comparison of the ECMWF reanalysis with FIRE I observations: Diurnal variation of marine stratocumulus. J. Climate, 14, 1466-1478.

— tions of the diurnal cycle of the EUROCS stratocumulus case. Quart. J. Roy. Meteor. Soc., 130, 3269-3296.

Fairall, C. W., E. F. Bradley, D. P. Rogers, J. B. Edson, and G. S. Young, 1996: Bulk parameterization of air-sea fluxes for Tropical Ocean-Global Atmosphere Coupled-Ocean Atmosphere Response Experiment. J. Geophys. Res., 101, 3747-3764.

Garreaud, R. D., and R. Muñoz, 2004: The diurnal cycle in circulation and cloudiness over the subtropical southeast Pacific: A modeling study. J. Climate, 17, 1699-1710.

GFDL Global Atmospheric Model Development Team, 2004: The new GFDL Global Atmosphere and Land Model AM2-LM2: Evaluation with prescribed SST simulations. J. Climate, 17, 4641-4673.

Gibson, J. K., P. Källberg, S. Uppala, A. Hernandez, A. Nomura, and E. Serrano, 1997: ERA description. ECMWF Reanalysis Project Report Series 1, 72 pp.

Grenier, H., and C. S. Bretherton, 2001: A moist PBL parameterization for large-scale models and its application to subtropical cloud-topped marine boundary layers. Mon. Wea. Rev., 129, 357-377.

Hack, J. J., 1994: Parameterization of moist convection in the National Center for Atmospheric Research Community Climate Model (CCM2). J. Geophys. Res., 99, 5541-5568.

_ J. M. Caron, S. G. Yeager, K. W. Oleson, M. M. Holland, J. E. Truesdale, and P. J. Rasch, 2006: Simulation of the global hydrological cycle in the CCSM Community Atmosphere Model version 3 (CAM3): Mean features. J. Climate, 19, 2199-2221.

Hoinka, K. P., 2007: Semi-diurnal pressure fluctuation in the ERA40 data. Meteor. Z., 16, 255-260.

Holtslag, A. A. M., and B. A. Boville, 1993: Local versus nonlocal boundary-layer diffusion in a global climate model. J. Climate, 6, 1825-1842.

Hurrell, J. W., J. J. Hack, D. Shea, J. M. Caron, and J. Rosinski, 2008: A new sea surface temperature and sea ice boundary data set for the Community Atmosphere Model. J. Climate, 21, 5145-5153.

Kiehl, J. T., and P. R. Gent, 2004: The Community Climate System Model, version 2. J. Climate, 17, 3666-3682.

King, M. D., and Coauthors, 2003: Cloud and aerosol properties, precipitable water, and profiles of temperature and water 
vapor from MODIS. IEEE Trans. Geosci. Remote Sens., 41, 442-458, doi:10.1109/TGRS.2002.808226.

Klein, S. A., and D. L. Hartmann, 1993: The seasonal cycle of low stratiform clouds. J. Climate, 6, 1587-1606.

— X. X. Jiang, J. Boyle, S. Malyshev, and S. Xie, 2006: Diagnosis of the summertime warm and dry bias over the U.S. Southern Great Plains in the GFDL climate model using a weather forecasting approach. Geophys. Res. Lett., 33, L18805, doi:10.1029/2006GL027567.

Köhler, M., 2005: Improved prediction of boundary layer clouds. ECMWF Newsletter, No. 104, ECMWF, Reading, United Kingdom, 18-22. [Available online at http://www.ecmwf.int/ publications/newsletters/pdf/104.pdf.]

Lock, A. P., 2001: The numerical representation of entrainment in parameterizations of boundary layer turbulent mixing. Mon. Wea. Rev., 129, 1148-1163.

—, A. R. Brown, M. R. Bush, G. M. Martin, and R. N. B. Smith, 2000: A new boundary layer mixing scheme. Part I: Scheme description and single-column model tests. Mon. Wea. Rev., 128, 3187-3199.

Ma, C.-C., C. R. Mechoso, A. W. Robertson, and A. Arakawa, 1996: Peruvian stratus clouds and the tropical Pacific circulation: A coupled ocean-atmosphere GCM study. J. Climate, 9, 1635-1645.

Martin, G. M., D. W. Johnson, and A. Spice, 1994: The measurement and parameterization of effective radius of droplets in warm stratocumulus clouds. J. Atmos. Sci., 51, 1823-1842.

Mechoso, C. R., and Coauthors, 1995: The seasonal cycle over the tropical Pacific in coupled ocean-atmosphere general circulation models. Mon. Wea. Rev., 123, 2825-2838.

— Land Study (VOCALS). VOCALS Science Plan, 42 pp. [Available online at http://www.eol.ucar.edu/projects/vocals/ science_planning/VOCALS-Science-Plan.pdf.]

Moeng, C.-H., and Coauthors, 1996: Simulation of a stratocumulustopped planetary boundary layer: Intercomparison among different numerical codes. Bull. Amer. Meteor. Soc., 77, 261-278.

Moorthi, S., and M. J. Suarez, 1992: Relaxed Arakawa-Schubert: A parameterization of moist convection for general circulation models. Mon. Wea. Rev., 120, 978-1002.

Onogi, K., and Coauthors, 2007: The JRA-25 Reanalysis. J. Meteor. Soc. Japan, 85, 369-432.

Park, S., and C. S. Bretherton, 2009: The University of Washington shallow convection and moist turbulence schemes and their impact on climate simulations with the Community Atmosphere Model. J. Climate, in press.

Petch, J. C., M. Willett, R. Y. Wong, and S. J. Woolnough, 2007: Modelling suppressed and active convection. Comparing a numerical weather prediction, cloud-resolving and singlecolumn model. Quart. J. Roy. Meteor. Soc., 133, 1087-1100.

Phillips, T. J., and Coauthors, 2004: Evaluating parameterizations in general circulation models: Climate simulation meets weather prediction. Bull. Amer. Meteor. Soc., 85, 1903-1915.

Platnick, S., M. D. King, S. A. Ackerman, W. P. Menzel, B. A. Baum, J. C. Riédi, and R. A. Frey, 2003: The MODIS cloud products: Algorithms and examples from Terra. IEEE Trans. Geosci. Remote Sens., 41, 459-473, doi:10.1109/TGRS.2002.808301.

Pope, V. D., J. A. Pamment, D. R. Jackson, and A. Slingo, 2001: The representation of water vapor and its dependence on vertical resolution in the Hadley Centre Climate Model. J. Climate, 14, 3065-3085.
Rasch, P. J., and J. E. Kristjansson, 1998: A comparison of the CCM3 model climate using diagnosed and predicted condensate parameterizations. J. Climate, 11, 1587-1614.

Rossow, W. B., and R. A. Schiffer, 1999: Advances in understanding clouds from ISCCP. Bull. Amer. Meteor. Soc., 80, 2261-2288.

Rotstayn, L. D., B. F. Ryan, and J. J. Katzfey, 2000: A scheme for calculation of the liquid fraction in mixed-phase stratiform clouds in large-scale models. Mon. Wea. Rev., 128, 1070-1088.

Rozendaal, M. A., C. B. Leovy, and S. A. Klein, 1995: An observational study of diurnal variations of marine stratiform cloud. J. Climate, 8, 1795-1809.

Schubert, W. H., J. S. Wakefield, E. J. Steiner, and S. K. Cox, 1979: Marine stratocumulus convection. Part I: Governing equations and horizontally homogeneous solutions. J. Atmos. Sci., 36, 1286-1307.

Siebesma, A. P., and J. W. M. Cuijpers, 1995: Evaluation of parametric assumptions for shallow cumulus convection. J. Atmos. Sci., 52, 650-666.

— convective boundary layer: Description and 1D results. Proc. 14th Symp. on Boundary Layers and Turbulence, Aspen, CO, Amer. Meteor. Soc., 4.16.

— , and Coauthors, 2004: Cloud representation in generalcirculation models over the northern Pacific Ocean: A EUROCS intercomparison study. Quart. J. Roy. Meteor. Soc., 130, 3245-3267.

—, P. M. M. Soares, and J. Teixeira, 2007: A combined eddydiffusivity mass-flux approach for the convective boundary layer. J. Atmos. Sci., 64, 1230-1248.

Slingo, J. M., 1987: The development and verification of a cloud prediction scheme for the ECMWF model. Quart. J. Roy. Meteor. Soc., 113, 899-927.

Soares, P. M. M., P. M. A. Miranda, A. P. Siebesma, and J. Teixeira, 2004: An eddy-diffusivity/mass-flux parameterization for dry and shallow cumulus convection. Quart. J. Roy. Meteor. Soc., 130, 3365-3384.

Stevens, B., and Coauthors, 2003: Dynamics and Chemistry of Marine Stratocumulus-DYCOMS-II. Bull. Amer. Meteor. Soc., 84, 579-593.

— via observations of nocturnal marine stratocumulus. Mon. Wea. Rev., 133, 1443-1462.

_ A. Beljaars, S. Bordoni, C. Holloway, M. Köhler, S. Krueger, V. Savic-Jovcic, and Y. Zhang, 2007: On the structure of the lower troposphere in the summertime stratocumulus regime of the northeast Pacific. Mon. Wea. Rev., 135, 985-1005.

Taylor, K. E., D. Williamson, and F. Zwiers, 2000: The sea surface temperature and sea-ice concentration boundary conditions for AMIP II simulations. PCMDI Rep. 60, 28 pp. [Available online at http://www-pcmdi.llnl.gov/publications/pdf/60.pdf.]

Teixeira, J., P. May, M. Flatau, and T. F. Hogan, 2008: SST sensitivity of a global ocean-atmosphere coupled system to the parameterization of boundary layer clouds. J. Mar. Syst., 69, 29-36, doi:10.1016/j.jmarsys.2007.02.012.

Tiedtke, M., 1989: A comprehensive mass flux scheme for cumulus parameterization in large-scale models. Mon. Wea. Rev., 117, 1779-1800.

_ 1993: Representation of clouds in large-scale models. Mon. Wea. Rev., 121, 3040-3061.

Tompkins, A. M., 2002: A prognostic parameterization for the subgrid-scale variability of water vapor and clouds in large-scale 
models and its use to diagnose cloud cover. J. Atmos. Sci., 59 1917-1942.

- - and Coauthors, 2004: Moist physical processes in the IFS: Progress and plans. ECMWF Tech. Memo. 452, $91 \mathrm{pp}$. [Available online at http://www.ecmwf.int/publications/library/ ecpublications/_pdf/tm/401-500/tm452.pdf.]

Uppala, S. M., and Coauthors, 2005: The ERA-40 Re-Analysis. Quart. J. Roy. Meteor. Soc., 131, 2961-3012, doi:10.1256/ qj.04.176.

vanZanten, M. C., and B. Stevens, 2005: Observations of the structure of heavily precipitating marine stratocumulus. J. Atmos. Sci., 62, 4327-4342.

Whiteman, C. D., and X. Bian, 1996: Solar semidiurnal tides in the troposphere: Detection by radar profilers. Bull. Amer. Meteor. Soc., 77, 529-542.

Willett, M. R., P. Bechtold, D. L. Williamson, J. C. Petch, S. F. Milton, and S. J. Woolnough, 2008: Modelling suppressed and active convection: Comparisons between three global atmosphere models. Quart. J. Roy. Meteor. Soc., 134, 1881-1896.

Williamson, D. L., and J. G. Olson, 2007: A comparison of forecast errors in CAM2 and CAM3 at the ARM Southern Great Plains Site. J. Climate, 20, 4572-4585.

—- and Coauthors, 2005: Moisture and temperature balances at the Atmospheric Radiation Measurement Southern Great Plains Site in forecasts with the Community Atmosphere Model (CAM2). J. Geophys. Res., 110, D15S16, doi:10.1029/ 2004JD005109.

Wittenberg, A. T., A. Rosati, N.-C. Lau, and J. J. Ploshay, 2006: GFDL's CM2 global coupled climate models. Part III: Tropical Pacific climate and ENSO. J. Climate, 19, 698-722.

Wood, R., and C. S. Bretherton, 2004: Boundary layer depth, entrainment, and decoupling in the cloud-capped subtropical and tropical marine boundary layer. J. Climate, 17, 3576-3588.
- — - and D. L. Hartmann, 2002: Diurnal cycle of liquid water path over the subtropical and tropical oceans. Geophys. Res. Lett., 29, 2092, doi:10.1029/2002GL015371.

— — B B. Huebert, C. R. Mechoso, and R. Weller, 2007: VOCALS: The VAMOS Ocean-Cloud-Atmosphere-Land Study. WCRP and Cosponsors Program Summary, 9 pp. [Available online at http://www.eol.ucar.edu/projects/vocals/ documentation/vocals_overview.pdf.]

Wyant, M. C., and Coauthors, 2007: A single-column model intercomparison of a heavily drizzling stratocumulus-topped boundary layer. J. Geophys. Res., 112, D24204, doi:10.1029/ 2007JD008536.

Xu, K.-M., and S. K. Krueger, 1991: Evaluation of cloudiness parameterizations using a cumulus ensemble model. Mon. Wea. Rev., 119, 342-367.

Zhang, G. Z., and N. A. McFarlane, 1995: Sensitivity of climate simulations to the parameterization of cumulus convection in the Canadian Climate Centre General Circulation Model. Atmos.-Ocean, 33, 407-446.

Zhang, M., W. Lin, C. S. Bretherton, J. J. Hack, and P. J. Rasch, 2003: A modified formulation of fractional stratiform condensation rate in the NCAR Community Atmospheric Model (CAM2). J. Geophys. Res., 108, 4035, doi:10.1029/2002JD002523.

Zhu, P., and Coauthors, 2005: Intercomparison and interpretation of single-column model simulations of a nocturnal stratocumulustopped marine boundary layer. Mon. Wea. Rev., 133, 27412758.

Zuidema, P., and D. L. Hartmann, 1995: Satellite determination of stratus cloud microphysical properties. J. Climate, 8, 1638-1657.

, E. R. Westwater, C. Fairall, and D. Hazen, 2005: Shipbased liquid water path estimates in marine stratocumulus. J. Geophys. Res., 110, D20206, doi:10.1029/2005JD005833. 